\title{
La rosa en la poesía de amor del siglo XV
}

\author{
Álvaro Alonso \\ Universidad Complutense de Madrid
}

Título: La rosa en la poesía de amor del siglo XV.

Resumen: En el presente trabajo analizo las diferentes funciones que la rosa tiene en la poesía del siglo XV: a) La rosa como metáfora de la belleza de la amada. En esta formulación, el color de la flor es irrelevante; b) La rosa roja o rosa como metáfora de las mejillas de la amada; c) La rosa roja para los labios femeninos; d) La rosa como regalo de la amada y el jardín de rosas como escenario en el que se mueve; y e) El amor y sus sufrimientos como rosa entre espinas.

Palabras clave: Poesía de cancionero, metáfora, descriptio puellae.

Fecha de recepción: 22/4/2013.

Fecha de aceptación: 27/5/2013.
Title: The Rose in $15 \mathrm{~h}$ Century Love Poetry.

Abstract: In this essay I study the different roles the rose plays in XVth century Spanish love poetry: a) The rose as a metaphor for the beloved's beauty; b) The red or the pink rose as a metaphor of the beloved cheeks; c) The red rose for the lips; d) The rose as a present to the beloved, or the garden as the scene where she walks; and e) Love and its pains as a rose and its thorns.

Key words: Cancionero poetry, metaphor, descriptio puellae.

Date of Receipt: 22/4/2013.

Date of Approval: 27/5/2013.

Lejos de su triunfo en la poesía de los siglos XVI y XVII, la rosa ocupa en la poesía cuatrocentista un lugar que, pese a todo, no es desdeñable. El carácter muy abstracto de la poesía amorosa cancioneril no impide que aparezcan las flores con cierta frecuencia, en tanto que la poesía religiosa muestra una clara tendencia, que viene, obviamente, de muy lejos, a identificar a la Virgen María con la rosa, junto con otros usos metafóricos menos frecuentes. En total, la Dutton Editions del Electronic Corpus of 15th Century Castilian "Cancionero" Manuscripts recoge aproxi- 
madamente unos ciento cincuenta casos en los que aparece la palabra rosa y sus derivados ${ }^{1}$.

Valiéndome de ese corpus, me propongo analizar la rosa como motivo poético en los poemas amorosos del siglo XV. Mi intención es comprender mejor no solo la producción poética cancioneril, sino también deslindar lo que hay de nuevo y de heredado en los autores de los siglos XVI y XVII.

\section{IDENTIFICACIONES GENÉRICAS ENTRE LA ROSA Y LA MUJER}

Son relativamente numerosos los casos en los que la rosa aparece como arquetipo de belleza, lo que permite compararla (o identificarla metafóricamente) con la amada y, más genéricamente, con cualquier mujer objeto de elogio. Entre los poetas más conocidos de la lírica cancioneril, cabe recordar a Juan de Mena, quien sitúa a su señora por encima de todas las demás: "vos vedes como las rosas / deleitosas / se terminan en la sarças". Pero también el marqués de Santillana, en el elogio de la vaquera de la Finojosa: "Non creo las rosas / de la primavera / sean tan hermosas"; y Alonso Pérez compara a "cuatro rameras cortesanas" con "el granado rosal / plantado do no da el aire"2. El cancionero de Jiménez de Urrea incluye un poema en el que el autor describe pormenorizadamente el cuerpo de la amada. Contra lo que cabría esperar, la rosa no aparece en esa descripción y sí en cambio en el elogio final de la cordura de la muchacha: "en saber, gracia y cordura / es más linda que la rosa" ${ }^{3}$. Es decir, que la flor aparece

1 An Electronic Corpus of 15th Century Castilian Cancionero Manuscripts - http:// cancionerovirtual.liv.ac.uk. Para rosa* se registran 106 casos; para rrosa*, 44; para rossa*, 8; y para rrossa*, 22. Pero habría que descontar los textos repetidos y aquellos que, incluyendo la sucesión "rosa" no son derivados de esa palabra. Recurro solo a la Dutton Editions porque me interesa fundamentalmente la producción lírica. De dicho corpus proceden todas mis citas, salvo indicación contraria, si bien retoco la ortografía.

2 Juan de Mena, "Muy más clara que la luna", en BM1, vv. 32-34 (ID 2329); Iñigo López de Mendoza, "Moça tan fermosa", en SA8, vv. 21-23 (ID 3434); Alonso Pérez, "Caminando en un vegel", en 13*FC, vv. 9-10 (ID 6080).

3 Pedro Manuel Jiménez de Urrea, "Es mi amiga tan graciosa", en 13UC, vv. 33-34 (ID 4891); y para la réplica a Torrellas "Torrellas y Hernán Mexía”, en 13UC, v. 
no como arquetipo de la belleza sino de la perfección en cualquier ámbito. Una idea parecida es la que se encuentra en el propio Urrea cuando, replicando a Torrellas, dice de las mujeres que ellas son "las mismas rosas".

Puesto que lo que interesa de la flor es, genéricamente, su belleza o, de manera aun más abstracta, su perfección, sus rasgos sensoriales concretos carecen de relevancia. Así, por ejemplo, es indiferente de qué color sean las rosas objeto de comparación. Solo excepcionalmente esos rasgos adquieren interés, pero más por su valor simbólico que en sí mismos. Es lo que ocurre en el conocido poema de Nicolás Núñez "porque su amiga le dio una rosa". Cuando el poeta afirma de la rosa "lo verde me dio esperanza, / lo blanco me la negó", la blancura de la flor remite a la castidad de la mujer o, quizá, al amor infeliz ${ }^{4}$. Esa referencia alegórica, frecuente en la poesía religiosa, es casi única en la poesía amorosa, si se exceptúa, quizá, un poema de Juan del Encina, "Juan del Encina a una señora que le dio un manojo de alhelíes blancos y morados con otras flores que se llaman maravillas, andándose espaciando por el campo”. El poeta no quiere correr riesgos:
Quiero, señora, tomar
lo cierto, por acertar,
en estas flores y rosas:
que las blancas y olorosas
demuestran vuestras primores 5 .

No es fácil precisar si los dos adjetivos se refieren exclusivamente al sustantivo "flores" (y habría que pensar entonces en los alhelíes del epígrafe), o

123 (ID 7545).

4 Nicolás Núñez, "Rosa, si rosa me distes", en 11CG (ID 6228). Sobre el poema de Nicolás Núñez y su valor simbólico, Keith Whinnom, La poesía amatoria cancioneril en la época de los Reyes Católicos, Durham, University of Durham, 1981, pp. 42-43 y 52-54; Alan Deyermond, "The Poetry of Nicolás Núñez", en Alan Deyermond e Ian Macpherson (ed.), The Age of the Catholic Monarchs, 1474-1516: Literary Studies in Memory of Keith Whinnom, Liverpool, Liverpool University Press, 1989, pp. 25-36. Sobre el blanco en relación con el amor infeliz, Jeanne Battesti-Pelegrin, Lope de Stúñiga. Recherches sur la poésie espagnole du XVème siècle, Aix-en-Provence, Université de Provence, 1982, I, p. 403.

5 Juan del Encina, "Mi bien y señora mía", en 96JE, vv. 23-27 (ID 4472). 
si califican también a las rosas. A la vista del poema de Nicolás Núñez, me parece más probable esta segunda hipótesis, que asigna a las flores el mismo color, y el mismo valor alegórico, que el poema "Rosa, si rosa me distes”. Más aun, dada la coincidencia cronológica de los dos poetas, no me parece improbable que haya una relación directa entre los versos de uno y de otro.

Conviene observar que, además de coincidir en el color, las rosas de Encina y las de Nicolás Núñez coinciden en su perfume. La "rosa olorosa" es un tópico repetidísimo en la poesía religiosa, pero no faltan ejemplos en la poesía de amor. Así, en una glosa al romance de Rosaflorida, se parafrasea de esta forma el nombre de la protagonista:

Rosa de nuevos olores, triumfante triumfo de amor [...]

de las más lindas la flor ${ }^{6}$.

No parece que estos versos inviten a establecer una relación "perfume de la rosa = perfume de la amada", como, por el contrario, ocurre en la poesía de los Siglos de Oro. Al igual que en los poemas dedicados a la Virgen, el aroma de la rosa es aquí, simplemente, un rasgo más de su perfección, y es ese vago valor ponderativo (y no una precisa equivalencia sensorial) lo que permite llamar a la amada "rosa de nuevas olores". Varias de las referencias al perfume de la rosa que encuentro en la poesía amorosa cancioneril son de esta naturaleza, con excepción de los poemas de Nicolás Núñez y, tal vez, Encina y Francisco Imperial. Cuando el primero dice "el olor vos lo pusistes" remite al perfume de la amada junto con el de la flor; cuando Encina asegura "que las blancas y olorosas demuestran vuestras primores", es difícil saber si los primores de la dama son su castidad y su perfume, o si las rosas olorosas recuerdan genéricamente la perfección de la mujer ${ }^{7}$. Lo mismo puede decirse de la referencia al perfume de la rosa que se encuentra en la composición de Imperial "Solo en l'alva pensoso estando" .

6 "Porque en tal caso y tenor", en 20*RN, vv. 51-55 (ID 5068).

7 Nicolás Núñez, "Rosa, si rosa me distes" cit., v. 9; Juan del Encina, "Mi bien y señora mía” cit., vv. 26-27.

8 Francisco Imperial, "Solo en l' alva pensoso estando", en SA7, vv. 25-30 (ID 2685). 
De una manera general, y atendiendo a la cronología, hay que señalar que estas comparaciones entre la belleza de la rosa y la de la mujer se dan a lo largo de todo el siglo. Da la impresión (que habría que confirmar con cómputos más precisos) que son los primerísimos y los últimos poetas de cancionero los que con más frecuencia recurren a este uso poético de la rosa. Imperial y Villasandino, por un extremo, y Encina y Jiménez de Urrea, por el otro, parecen especialmente aficionados a este tipo de metáforas y símiles florales. No sería sorprendente que la imagen de la rosa fuera más frecuente antes de que se consolidara la tendencia a la abstracción de la poesía cancioneril y cuando dicha tendencia empieza a relajarse. En todo caso, la diferencia sería puramente cuantitativa, puesto que poetas del pleno Cuatrocientos (Mena y Santillana) no ignoran ni mucho menos esas comparaciones.

\section{COMPARACIONES ENTRE LA ROSA Y UNA PARTE DEL CUERPO FEMENINO}

A diferencia de lo que ocurrirá luego en la poesía de los Siglos de Oro, las comparaciones y metáforas de esta naturaleza son raras en la poesía cancioneril. En contraste con los casos del apartado anterior, aquí importa mucho el color de la flor. Vale la pena recoger todos los ejemplos que pueden espigarse en el corpus de Dutton, empezando por aquellos en los que la rosa se relaciona con las mejillas o, más genéricamente, con la tez de la mujer.

1. En el romance "Estase la gentil dama", la protagonista se autodescribe elogiosamente:

Blanca soy como el papel,

la color tengo mezclada

como rosa en el rosel ${ }^{9}$.

9 “Estase la gentil dama”, en 17*OM, vv. 30-32 (ID 5042). 
La expresión "color mezclada" se refiere, sin duda, al color sonrosado, mezcla de rojo y blanco, y evoca inmediatamente el conocido elogio de Melibea en la Celestina:

La tez, lisa, lustrosa, el cuero suyo oscurece la nieve; la color, mezclada, qual ella la escogió para $\sin ^{10}$.

El esquema es el mismo en los dos casos: se comienza hablando del blanco de la piel ("blanca soy como el papel", "el cuero suyo oscurece la nieve"), que transparenta el rojo de la sangre: el resultado es "la color mezclada" que hace la belleza de Melibea y de la "gentil dama" del romance. En cuanto a la precisión "como rosa en el rosel", muestra que para el poeta la rosa arquetípica es la de color rosa.

El poema presenta la comparación en sus versiones tardías, ya que en la versión primitiva de Jaime d' Olesa no hay referencia alguna al color de la "gentil dona".

2. Alfonso Álvarez de Villasandino, escribiendo en nombre de Pedro Manrique, enamorado de la hija del duque de Benavente, elogia así la belleza de la muchacha:

vuestra color matizada

más que rosa del rosal

me tormenta e desordena ${ }^{11}$.

"Color matizada" es, claramente, sinónimo de "color mezclada"; y la comparación se expresa, casi formulísticamente, como en el romance de la dama y el rústico pastor: "como (o más que) rosa del rosal".

3. El marqués de Santillana se encuentra a la mozuela de Bores y la elogia en los siguientes términos:

10 Fernando de Rojas, Comedia o tragicomedia de Calisto y Melibea, ed. Peter E. Russell, Madrid, Castalia, 1991, p. 231.

11 Alfonso Álvarez de Villasandino, "Señora, flor de azucena", en PN1, vv. 11-13 (ID 1155). 
La cara placiente, fresca como rosa, de tales colores cual nunca vi dama nin otra, señores ${ }^{12}$.

Aquí la comparación con la rosa alude a la frescura, pero es revelador que inmediatamente aparezca la referencia al color.

4. De nuevo el marqués de Santillana, en unos versos “a sus fijas, loando su hermosura", dice "las mexillas como rosas", sin mayores precisiones. La comparación alude, probablemente, a la frescura y al color de las mejillas de las muchachas que, vale la pena señalarlo, se presentan como serranas ${ }^{13}$.

5. El poema que Juan del Encina escribió "alabando a su amiga" contiene la siguiente descripción:

Las mexillas muy hermosas

$\mathrm{y}$ vistosas $[\ldots]$

de suyo muy coloradas,

como rosas

muy perfectas y graciosas ${ }^{14}$.

De nuevo, lo más natural es suponer que la dama tiene las mejillas sonrosadas. La expresión "muy coloradas" no deberá entenderse, entonces, como "muy rojas", sino como "intensamente teñidas". Así parece confirmarlo un texto de fray Martín de Córdoba en el que se explica por qué Santa Inés se negó a utilizar afeites: "mis mejillas están coloradas con la sangre de Aquel cuya madre es virgen"15. Otra vez la idea de una piel (blanca,

12 Iñigo López de Mendoza, "Moçuela de Bores”, en SA8, vv. 13-17 (ID 3431).

13 Iñigo López de Mendoza, "Dos serranas he trobado", en SA1, v. 18 (ID 3061).

14 Juan del Encina, "Pues que tanto me mostráis", en 96JE, vv. 67-72.

15 Fray Martín de Córdoba, Jardín de nobles doncellas, ed. Félix García, Madrid, Ediciones Religión y Cultura, 1956, p. 147, pero cito por REAL ACADEMIA ESPAÑOLA: Banco de datos (CORDE) [en línea] Corpus diacrónico del español <http://www.rae. es [15-VII-2011] 
debemos suponer), que recibe su color (“están coloradas”), del rojo de la sangre: en este caso, de Cristo. De manera que las rosas de Encina son, de nuevo, de color rosa.

6. El último poema donde encuentro la comparación es un texto del Cancionero musical de Elvas, de ambientación pastoril. En él, el pastor hace el elogio de su pastora diciendo: "Ella es blanca y colorada, / como la rosa y la leche"16. De nuevo el ideal femenino es el de "la color mezclada" de Melibea; pero es dudoso que en este caso las rosas a las que se refiere el poema sean de color rosa. Los versos quizá queden más claros a la luz de un nuevo texto de fray Martín de Córdoba, correspondiente también al Jardín de nobles doncellas. Allí el autor explica que la vergüenza da realce a la virginidad, y añade la siguiente comparación:

Pues si queremos hacer una guirnalda, y toda es de lirios, es mucho blanca y no es tan hermosa como si le interponemos alguna rosa colorada [...]. Pues si cuando la mujer se pinta la cara lo hace todo albayalde, será mucho blanca; y, por ende, es bien que mezcle el albayalde con el arrebol, para que haga suave color $^{17}$.

Naturalmente, la "rosa colorada" representa la vergüenza, que hace aún más bello el blanco lirio de la virginidad. Pero, más allá del valor alegórico, conviene destacar dos aspectos en el párrafo. En primer lugar, el ideal de belleza femenina es, también para fray Martín, el del color sonrosado. Así que el ideal no solo es poético o literario sino que corresponde a una, ya entonces, extendida convención social, de la que el moralista se hace aquí portavoz.

Pero ese color no aparece representado mediante la rosa, sino mediante la suma del lirio más la rosa colorada, paralela a la del albayalde más el arrebol:

$$
\begin{aligned}
& \text { lirio + "rosa colorada" - "suave color" } \\
& \text { albayalde + arrebol - "suave color" }
\end{aligned}
$$

16 "Vámonos, Juan, al aldea”, en EH1, vv. 5-6 (ID 3611).

17 Fray Martín de Córdoba, ob. cit., p. 272. 
A la vista de esa doble equivalencia habrá que concluir que, en este caso, "rosa colorada" sí es sinónimo de "rosa roja": así lo indican su equivalencia con el arrebol, por una parte, y, por otra, su función de matizar la blancura del lirio (función que difícilmente podría cumplir una de color rosa).

Si regresamos ahora a los versos pastoriles del Cancionero de Elvas, la situación parece la misma. En la expresión "blanca y colorada como la rosa y la leche", "blanca" corresponde a "leche"y "colorada" (="roja") corresponde a "rosa". De manera que tenemos una equivalencia idéntica a las dos propuestas por fray Martín de Córdoba:

lirio + "rosa colorada" - "suave color, color mezclada" albayalde + arrebol - "suave color, color mezclada" leche + rosa (colorada) - "suave color, color mezclada"

Si la interpretación que propongo es correcta, tendríamos una doble función de la rosa a la hora de caracterizar metafóricamente el color de la mujer ${ }^{18}$. En algunos casos, los versos aluden a una rosa rosa que, por sí sola, evoca el color perfecto de la tez femenina. En otros, la rosa evocada es la rosa roja que, para equipararse con el color de la mujer, necesita rebajar su intensidad con un elemento blanco (lirio, leche, etc.). En los cinco primeros textos tenemos el primer uso de la rosa; en el último, el segundo. Cabe preguntarse si uno y otro planteamiento tienen orígenes y fuentes diferentes.

Si se compara el uso de la metáfora (o el símil) en la poesía cuatrocentista con lo que ocurre en la poesía posterior, llama la atención la escasez de los testimonios: una de las metáforas preferidas de la poesía renacentista y barroca apenas se encuentra en la poesía cancioneril. Vale la pena observar, además, que de esos seis testimonios, cuatro corresponden a composiciones de ambientación pastoril y popularizante: el romance de la gentil dama y el rústico pastor, la serranilla de la mozuela de Bores y la "serranilla" a sus hijas del marqués de Santillana, y el poema del Cancionero de Elvas.

18 Tomo esta idea de la doble función de la rosa de Javier de la Peña, Flores en la poesía española del Renacimiento y Barroco, tesis doctoral, Madrid, Universidad Complutense, 2009. 
No parece casual que uno de los dos poemas en los que la imagen se aplica a una amada propiamente cortesana sea obra de Juan del Encina, es decir, un poeta de extensa producción bucólica. Da la impresión de que su obra pastoril debió de influir aquí en la poesía cortesana del autor. No obstante, otros modelos debieron de influir en Encina a la hora de recuperar la imagen de las mejillas de rosa. Podría pensarse, por ejemplo, en modelos petrarquescos o boccaccianos, pero también en la prosa sentimental o caballeresca castellana.

En un excelente análisis del poema de Encina, Álvaro Bustos observa que la descripción de la amada corresponde aquí al llamado "canon largo", menos típico del petrarquismo que el "canon breve"19. En el primero se describe todo el cuerpo de la mujer, desde la cabeza a los pies (o a la cintura, como en el caso de Encina); en el segundo se describe solo el rostro y un único elemento (habitualmente el seno o las manos) del resto del cuerpo. Más aun: en el "canon breve", se omiten sistemáticamente algunas partes de la cara, como la nariz o las orejas ${ }^{20}$. Ni en Encina, ni en ninguno de los cinco casos que he recogido, aparece el canon breve, es decir, el más característicamente petrarquesco. De hecho, me inclino a pensar, con Bustos Táuler, que los modelos narrativos (boccaccianos o hispanos) tuvieron un papel más importante que los petrarquistas en la composición de Encina.

En cualquier caso, los versos de "Pues que tanto me mostráis" recuperan para la poesía cortesana de amor una imagen desaparecida casi desde principios de siglo y destinada a tener un largo éxito en la poesía posterior. Claro que cuando esa imagen reaparezca en los poetas renacentistas lo hará (al menos en la mayoría de los casos) no por influencia de Encina sino del petrarquismo italiano.

Además de la imagen rosa-mejillas de la mujer, encuentro una comparación de la rosa con los labios femeninos. Se trata de los versos en los que Francisco Vaca describe a la condesa de Cherra: "la boca muy bien formada, / los labios como una rosa"21. La composición está ambientada cerca de Nápoles y, de hecho, el poeta se movía en los ambientes de la

19 Álvaro Bustos Táuler, La poesía de Juan del Encina. El cancionero de 1496, Madrid, FUE, 2009, pp. 137-138.

20 Giovanni Pozzi, "Sul luogo comune”, en Alternatim, Adelphi, 1996.

21 Francisco Vaca, "Señor marqués, do se cría", en 11CG, vv. 34-35 (ID 6106). 
corte aragonesa de Italia ${ }^{22}$. Teniendo en cuenta ese dato, me inclino a pensar que la influencia italiana tuvo, en este caso, un papel decisivo, aunque, de nuevo, nos encontramos con una descripción que corresponde al canon largo.

En un trabajo al que ya he hecho referencia, Giovanni Pozzi señaló que solo a partir de Bembo (es decir, desde 1525-1530), se produce una especialización de las metáforas referidas a la belleza femenina: la rosa se aplica a las mejillas; el coral (o el rubí), a los labios. Antes, los dos términos metafóricos se utilizan indistintamente para las dos partes del cuerpo femenino: de manera que hay mejillas de rosa y labios de coral, pero también mejillas de coral y labios de rosa. La comparación de Francisco Vaca corresponde, por tanto, a un primer momento en la evolución de las convenciones metafóricas para el cuerpo femenino. Su historia posterior está todavía por hacer, pero da la impresión de que también en la lírica española el coral y el rubí triunfan como imagen para los labios, al menos hasta 1580. A partir de ese momento vuelve la imagen floral para los labios femeninos, pero entonces será cada vez más el clavel, y no la rosa, el término metafórico preferido. Rosas y claveles que han de ser, aquí inequívocamente, de color rojo.

En cualquier caso, y al margen de los desarrollos posteriores, los labios de rosa de Francisco Vaca quedan como un ejemplo aislado en la poesía cuatrocentista. Si se compara ese dato con los seis casos de "mejillas de rosa”, se podría pensar que una cierta especialización existe ya en los cancioneros. Pero quizá, simplemente, es que, en la poesía del XV la boca es un objeto poético mucho menos frecuente que las mejillas o el color de la tez.

\section{OTRAS RELACIONES ENTRE LA AMADA Y LAS ROSAS}

Además de las relaciones metafóricas o de semejanza entre la rosa y la mujer, esta puede mantener con la flor un tipo de relación diferente.

22 Así se desprende de la dedicatorias contenidas en el "Índice de autores" de Brian Dutton, con la colaboración de Jinnen Krogstad, El cancionero del siglo XV: $c$. 1360-1520, Salamanca, Universidad, 1990-1991, VIII. 
1. La amada se mueve en un escenario floral. Algunos de los más conocidos poemas de la lírica cancioneril corresponden a esta situación. Así, Francisco Imperial encuentra a la dama que lo hará prisionero de amor "en una floresta de rosas e flores"23. Más avanzado el siglo, un conocido poema, que algunas fuentes atribuyen a Suero de Ribera y otras al marqués de Santillana, comienza:

Por una gentil floresta

de lindas flores e rosas, vide tres damas fermosas

que de amores han recuesta ${ }^{24}$.

De nuevo el marqués de Santillana encuentra a la vaquera de la Finojosa "en un verde prado de rosas e flores”; Fernán Pérez de Guzmán autoriza a Leonor de los Paños, destinataria de su poema, a mirar "prados, rosas e flores"; y Guevara recuerda haber visto a su amada "dançando so los rosales" 25 .

A Guevara corresponde, según el testimonio de SV2, el planteamiento más original: el de la amada que embellece (o embellecería) la naturaleza con su presencia. No solo aplacaría las tormentas, sino que transformaría la vegetación:

Si fuésedes, vos, serrana,

por estas sierras fraguosas,

la sierra, de muy ufana,

se tornarié toda llana

y los robles todo $\operatorname{rosas}^{26}$.

23 Francisco Imperial, "Solo en l' alva pensoso estando", cit., v. 2 (ID 2685).

24 "Por una gentil floresta”, en 13*RM (que lo atribuye a Santillana), vv.1-4 (ID 2475).

25 Iñigo López de Mendoza, "Moça tan fermosa", en SA8, vv. 13-14 (ID 3434);

Fernán Pérez de Guzmán (como se sabe algunos cancioneros atribuyen el texto a Macías), "El gentil niño Narciso", en PN1, vv. 33-41 (ID 0113); Guevara, "O desastrada ventura", en 11CG, vv. 71-72 (ID 0867): la referencia a los rosales falta en la versión de LB1.

26 Guevara, "Si fuésedes, vos, serrana", en SV2, vv.1-5 (ID 0876). El epígrafe dice "Guivara a su amiga, pasado el puerto con gran fortuna". En LB1 no aparece esa atribución. 
Me inclino a ver aquí una influencia de la poesía italiana, donde este motivo de la naturaleza transfigurada es frecuente.

Entre las actividades que la mujer desarrolla en el escenario floral al que me acabo de referir, adquiere un especial relieve la de coger rosas. La situación, como se sabe, es característica de la poesía tradicional, donde está cargada de connotaciones simbólicas, habitualmente asociadas con la pérdida de la virginidad. Los cancioneros tardíos recogen varios de esos textos, como el muy conocido "mi madre, por me dar placer /, a coger rosas m’ embía”27, o el que comienza:

Levanteme, o madre,

mañanica frida,

fui cortar la rosa,

la rosa florida ${ }^{28}$.

En una composición popularizante, Rodrigo de Reinosa invita a la muchacha: "Cogerás flores y rosas, / laureles y clavellinas". Excepcionalmente, el motivo se encuentra también en un texto muy alejado de esos tonos: en el poema de Francisco Imperial "Ay donas, porque tristura”, el enamorado ve a su dama, con otras "donas de alto lugar,/ cogiendo rosas e flores" 29 .

2. La rosa como regalo. Cuatro poemas presentan este motivo, de los cuales dos obedecen al mismo esquema: el de Nicolás Núñez "porque su amiga le dio una rosa”, y el de Juan del Encina "a una señora que le dio un manojo de alhelíes blancos y morados [...]"30. En ambos casos, las rosas que la mujer envía como regalo aluden metafóricamente a sus propias cualidades, por lo que me he referido ya a uno y otro poema en el apartado correspondiente.

27 "Aquella mora garrida", en MP4f, vv. 3-4 (ID 4018).

28 "Levanteme, o madre", en SV1, vv. 1-4 (ID 3510).

29 Rodrigo de Reinosa, "Si te vas a bañar, Juanica", en 17*RJ, vv. 59-60 (ID 4598);

Francisco Imperial, “Ay donas, porque tristura”, en PN1, vv. 15-16 (ID 0453).

30 Nicolás Núñez, "Rosa, si rosa me distes”, en 11CG (ID 6228) y "Mi bien y señora mía”, en 96JE (ID 4472). 
Distinto es el caso de la composición “Ocorrido m’a fablar”, en la que Hugo de Urríes relata la historia de amor con su mujer. En los primeros pasos de esa historia, y con objeto de tener un indicio de que ella le corresponde, el poeta le pide a la amada una prenda "es a saber, una rosa / que en los pechos yo te vi" 31 . A diferencia de lo que ocurre en los dos ejemplos anteriores, en este caso la composición no se centra en el regalo mismo, ni este alude alegóricamente a las cualidades de la dama. En cambio, es este uno de los poquísimos textos que encuentro en los que la rosa aparece como adorno del cuerpo femenino.

Un último ejemplo del motivo se encuentra en una composición pastoril del Cancionero musical de palacio, en la que el pastor promete una serie de regalos a su pastora:
Darl'e mil conejitos,
pardales y golondrinas,
flores, rosas, clavellinas ${ }^{32}$.

Por lo que se refiere a la cronología, los dos primeros poemas (el de Nicolás Núñez y el de Encina) son muy tardíos, como lo son todos los poemas “de regalo" en los cancioneros cuatrocentistas. También es tardío el poema pastoril, que recoge un tópico muy repetido en la tradición bucólica (el de los regalos del pastor a su pastora), desconocido, sin embargo, en la poesía de los cancioneros. El poema de LB2, en cambio, es bastante más antiguo, aunque conviene recordar que pertenece a un ámbito poético, el de la corte de Navarra, muy diferente al castellano.

\section{Otras RELACIONES ENTRE EL AMOR y LA ROSA}

Según se ha visto en los apartados anteriores, la rosa aparece asociada de una u otra forma a la mujer y, por tanto, al amor. De forma más abstracta, el amor aparece relacionado con las rosas en dos definitiones amoris. Una, de Juan del Encina, lo llama "rosa en abrojos"; otra, de Jimé-

31 Hugo de Urríes, “Ocorrido m' a fablar”, en LB2, vv. 186-187 (ID 2192).

32 "Gran plazer siento yo ya” en MP4c, vv. 24-26 (ID 3913). 
nez de Urrea, lo presenta como "laberinto de rosas" 33 . La idea de que no hay rosas sin espinas ni amores sin sufrimiento aparece también en una letra de justadores:

Sacó el Condestable de Castilla, don Iñigo Fernández de Velasco, un rosal con muchas rosas y una letra que decía:

En estas, y en las más cossas, hay más espinas que rossas ${ }^{34}$.

El poema podría interpretarse como una afirmación general sobre el mundo, pero dada la índole amorosa de la mayor parte de las letras de justadores, es muy probable que haya que entenderlo referido fundamentalmente a los sufrimientos de amor.

De una manera diferente, el amor, o su estación más propicia, se relaciona con las rosas en el poema de Jiménez de Urrea "En el placiente verano". El poeta cuenta que se enamoró en esa estación "cuando los lirios y rosas / nos dan los buenos olores" 35 . De forma análoga, aunque inversa, Francisco Imperial, al constatar su fracaso amoroso, "luego vi rosas e flores / todas secarse" 36 .

Queda, en fin, una composición que me resulta sintácticamente poco clara. Diego López de Haro se lamenta de una dama que lo ha abandonado:
Y tomadla como digo vuestra fe falsa, engañosa, que mi firmeza, la rosa, no sufre tener consigo falsa $\operatorname{cosa}^{37}$.

33 Juan del Encina [¿??], "Pues amas, triste amador", en 96JE, v. 27 (ID 6795); Pedro Manuel Jiménez de Urrea, "Es amor un pesamiento", en 13UC, v. 43 (ID 4728).

34 Iñigo Fernández de Velasco, "En estas, y en las más cossas", en MP2, vv. 1-2 (ID 2051).

35 Pedro Manuel Jiménez de Urrea, "En el placiente verano", en 13UC, vv. 11-12 (ID 4784).

36 Francisco Imperial, "Solo en l' alva pensoso estando", cit., vv. 93-95 (ID 2685).

37 Diego López de Haro, “O, que no hallo razón”, en 11CG, vv. 57-61 (ID 6080). 
Donde "la rosa" podría entenderse como un vocativo dirigido a la dama, pero tambíén como una aposición a "mi firmeza”: "mi firmeza en amor, tan perfecta como una rosa”.

\section{Conclusiones}

De las imágenes de la rosa en la poesía del siglo XV, la más frecuente es, sin duda, la que la convierte en metáfora de la belleza (o, más genéricamente, de la perfección) de la mujer. En ese uso, el color de la flor carece de importancia. Cuando aparece, se escoge la rosa blanca, claramente asociada con la castidad.

De forma más precisa (pero también más infrecuente), el color de la rosa se compara con el de las mejillas y, excepcionalmente, los labios de la figura femenina. Se escoge entonces la rosa rosa (para las mejillas) o la roja (para los labios; o para las mejillas, en unión con la leche u otro elemento blanco). Conviene observar que allí donde la rosa se menciona con ese valor descriptivo, lo hace siempre en el contexto del llamado "canon largo", y nunca en el "canon breve" que parece, por tanto, una radical novedad en la poesía del siglo XVI.

Junto al color se destaca el perfume de la rosa, bien como elemento que contribuye, genéricamente, a su perfección, bien para comparar explícitamente el olor de la flor con el de la amada.

La rosa aparece también como elemento importante del paisaje en el que se mueve la mujer, o como regalo que esta envía o recibe. Más vagamente, la flor se asocia con el amor, en formulaciones del tipo "el amor, como la rosa, tiene sus espinas" o "el amor es un laberinto de rosas".

En otro orden de cosas, hay que señalar que la imagen de la rosa es especialmente frecuente en la poesía pastoril o popularizante, al menos en dos formulaciones:

a) Las mejillas de la muchacha son del color de las rosas. Cuatro de los seis casos que encuentro corresponden a composiciones de ambientación pastoril, lo que, teniendo en cuenta que el corpus pastoril es relativamente minoritario, supone un claro desequilibrio a favor de este tipo de composiciones. 
b) La muchacha coge o corta rosas. El motivo es casi exclusivo de la lírica popular y popularizante.

En cambio, la imagen que equipara a la mujer con la rosa sencillamente por su belleza no parece especializada en la poesía de tipo popular.

En la poesía propiamente cortesana, la imagen de la rosa es especialmente frecuente en los poetas de principio y de final de siglo en las siguientes formulaciones:

c) La rosa se equipara a las mejillas y los labios de la mujer. Los tres ejemplos que encuentro corresponden uno a Villasandino, otro a Encina y un tercero (este para los labios) a Francisco Vaca, poeta del Cancionero general.

d) La rosa como regalo. De los cuatro ejemplos que encuentro, tres corresponden a finales de siglo: Nicolás Núñez, Encina y un poema pastoril del Cancionero musical de Palacio.

e) La rosa se relaciona más o menos vagamente con el amor. Imperial equipara un amor fracasado con una rosa que se seca; Jiménez de Urrea y Encina utilizan la rosa en sus definitiones amoris; y el Condestable don Ińigo Fernández de Velasco retoma la idea de que no hay amores ni rosas sin espinas.

Aunque no he efectuado recuentos precisos, parece que también la rosa como simple imagen de la belleza es más frecuente a comienzos y a finales de siglo que no en sus años centrales (si bien pueden citarse ejemplos en autores tan característicos del medio siglo como Juan de Mena).

Es difícil explicar ese descubrimiento (o redescubrimiento) de la rosa en los años finales del Cuatrocientos e iniciales del Quinientos. Sin duda, hay un conjunto mal definido de influencias (influencia de la lírica popular sobre la cortesana, modelos italianos, deslizamiento de ciertas imágenes desde la prosa al verso) que podrían dar cuenta de esa modificación. Será preciso, además, ampliar el análisis a la Severin-Maguire Editions, que permitirá conocer mejor los usos de la rosa, especialmente en la poesía religiosa, filosófica y moral. Mi impresión es que es en esos largos decires (por ejemplo en las descripciones de las figuras femeninas alegóricas y mitológicas, como las virtudes o las musas) es donde pueden encontrarse más y más variados usos del topos de la rosa. 